\title{
Nursing Students' Perceptions of Nursing Diagnoses and Clinical Decision-Making
}

\author{
Demet Inangil ${ }^{1}(\mathbb{D}$, Sengul Uzen Cura² (D) \\ ${ }^{1}$ University of Health Sciences, Hamidiye Faculty of Nursing, Istanbul, Turkey. \\ ${ }^{2}$ Canakkale Onsekiz Mart University, School of Medicine, Canakkale, Turkey. \\ Correspondence Author: Demet Inangil \\ E-mail: demet.inangil@sbu.edu.tr
}

Received: $21.05 .2019 \quad$ Accepted: 25.04 .2020

\begin{abstract}
Objective: The objective of this study was to evaluate nursing students' perceptions regarding nursing diagnoses and clinical decision-making skills level and to examine how these perceptions differ according to which nursing model was followed.

Methods: A descriptive, cross-sectional, comparative study was conducted. The study was carried out in one nursing department in Istanbul province and one nursing high school in Çanakkale province, Turkey. A total sample of 257 students participated. A Structured Information Form, Perception of Nursing Diagnoses Survey and Clinical Decision Making in Nursing Scale were used to collect data.

Results: $77.1 \%$ of the participants were women, with an average age of 19.09, and their average grade from the Fundamentals of Nursing course was $74.23 \pm 9.41$. The total of the PND score for the ADLs group was $2.45 \pm 0.55$, in the FHP group it was $2.31 \pm 0.27$. This difference in the incidence of value was not significant. The total of the CDMNS score means of the ADLs group was $147.44 \pm 12.95$, and the mean of the FHP group was $154.3 \pm 12.29$. A statistically significant difference was detected between the groups for the CDMNS score $(p=0.00)$.

Conclusion: From the results, it can be concluded that the use of nursing diagnoses is positively perceived by nursing students and their clinical decision-making perceptions are in the process of development. Nursing models that are used in nursing education may affect clinical decision making.

Keywords: Nursing models, diagnoses, decision making.
\end{abstract}

\section{INTRODUCTION}

Nursing is a profession which requires the combination of theoretical knowledge and psychomotor skills $(1,2)$. In the past, nursing education was focused on medical science, treatment of patients and routine nursing functions. Today, nursing practice is based on its own specially-developed nursing theory, and its own research $(3,4)$. The translation of scientific knowledge into nursing practice can take place only through the nursing process itself (5). The nursing process raises the quality of nursing health care and improves the effectiveness of individual patient care. Additionally, it improves the critical thinking and clinical decision-making skills of nurses (6).

It is expected from students graduating from nursing programs at Turkish universities that they meet the health care needs of patients using an individual and holistic approach, based on established nursing process and theory $(7,8)$. Importantly too, the publication of the 2010 Nursing Regulations by the Turkish Ministry of Health in 2010, with the inclusion of the phrase 'the nursing service applies the nursing process', meant in fact that the application of the nursing process became a legal obligation (9).

Assessment is the first step of the nursing process. Assessment should include all aspects of the individual in order to determine his or her overall state of health, in accordance with a particular nursing model. Nursing models guide nurses in how to gather data in a systematic and organised manner. They also help ensure that nursing care is provided in a scientific, planned and systematic way, based on a sound theoretical foundation $(10,11)$. The two models most commonly used today in nursing education are 'Activities of Daily Living: A Model for Nursing (ADLS)' developed by Roper, Logan, and Tierney (1996), and 'Functional Health Patterns (FHP)' developed by Gordon (1982). However, there is no data available to explain the reasons why one model has been chosen over the other for particular nursing 
programs in our country. Also, there is very little data as to the distinctions between the two models and their relative effectiveness in the context of individual care planning. The ADLs model has been adopted both in education and in nursing practice. It provides an easy method of assessment within the nursing process, as well as being readily applicable to both ill and healthy individuals. On the other hand, nursing diagnoses under NANDA-I (North American Nursing Diagnosis Association - International) are categorised according to Gordon's FHP (7) and it is considered that this model best facilitates the determination of correct nursing diagnosis. Because of this, the purpose of this study was to evaluate nursing students' perceptions regarding nursing diagnoses and clinical decision making and to compare how these perceptions differ according to which nursing model was followed.

\section{Research Questions}

- What are the students' perceptions regarding nursing diagnosis?

- What are the clinical decision-making perception scores of students?

- What is the difference of two models on nursing students' perceptions regarding nursing diagnosis and clinical decision making?

- What is the correlation between students' perceptions regarding nursing diagnoses and clinical decision making?

- What is the relationship between the exam notes of the Fundamentals of Nursing course and the clinical decisionmaking perception/nursing diagnosis perception scores of students?

\section{METHODS}

\subsection{Study Design}

A descriptive, cross-sectional, comparative, study was conducted. The study was carried out in one nursing department in Istanbul and Çanakkale provinces, Turkey.

\subsection{Sample}

The population of the study consisted of all 264 second grade students who successfully passed the Fundamentals of Nursing course and studied in the academic year 2016-2017. Therefore, there was no need for sample selection. The study was in fact completed with a total sample of 257 students, as a result of factors such as failure to complete collection forms and absence due to sick leave, or other reasons.

The students in both schools received the Fundamentals of Nursing I and II theoretical classes and clinical skills laboratory teaching, and over the same period they met and observed the care needs of at least seven patients in accordance with the nursing process. However, in order to diagnose patients in the course of the nursing process, one school used ADLs, while the other used FHP. During the theoretical classes which accompanied practical lessons, NANDA-I diagnoses were applied to the sample cases examined by students as part of their nursing process learning. Although the assessment phase was based on two different models, NANDA-I was used for nursing diagnosis in both schools.

\subsection{Instruments}

Prior to collecting the data, a short description about the study objectives was offered to the students before distributing the questionnaires. Students were instructed about their anonymity and confidentiality. It was guaranteed that they might be able to withdraw from the study in case they would like. The data were collected via face-to-face interviews in the classroom after the Fundamentals of Nursing final exam was announced. The following methods were used for the collection of data: a 'Structured Information Form' prepared by researchers, the 'Perception of Nursing Diagnoses Survey (PND)' and the 'Clinical Decision Making in Nursing Scale (CDMNS)'.

\subsection{Structured Information Form}

The Structured Information Form was prepared by the researchers on intervening variables, including the students' age, gender, their average grade from the Fundamentals of Nursing course and the school they were attending.

\section{Perception of Nursing Diagnoses Survey (PND)}

The PND Survey was developed by Olsen, Frost, and Orth (1991) with the aim of determining how students perceive nursing diagnoses. The survey consists of 30 items and 4 subscales: 'Delineation and promotion of nursing profession', 'Clear representation of patient's situation', 'Ease of Use', and 'Conceptual orientation'. The validity and reliability of its Turkish version was tested in 2013 by Akın-Korhan et al. When PND adapted to Turkey, the number of items in PND decreased to 26 from 30. The Cronbach's alpha value of the PND was 0.84. (12). In this study, the Cronbach's alpha value of the PND was 0.83. 5-point Likert scale was used, ranging from the 5 points assigned for 'I strongly agree' to 1 point for 'I strongly disagree'. The results were determined by dividing the points by the number of items, with the total score varying from 1 to 5 . A low total score on the scale indicates that students perceive the nursing diagnoses in a positive way (12). We are unaware of other research describing a significant difference in decision making between ADLs and FHP. We believe that this difference may explain when the research is carried out on this subject.

\section{Clinical Decision Making in Nursing Scale (CDMNS)}

The CDMNS measures the perceptions of nursing students in their own words with regard to clinical decision making. It was developed by Jenkins in 1983 and adapted for application in Turkey by Dicle and Durmaz in 2015. This original scale 
consisted of a total of 40 items, divided equally into four categories as follows: 'search for alternatives or options', 'canvassing of objectives and values', 'evaluation and reevaluation of consequences', and 'search for information and unbiased assimilation of new information'. The scale's Cronbach $\alpha$ value was found out to be 0.78 (13). In this study, the Cronbach's alpha value of the CDMNS was 0.71 . Twenty-two of the items carried a positive meaning, and 18 a negative one. Each item was assigned a frequency value as follows: 5=always, $4=$ often, $3=$ =sometimes, $2=$ rarely, and $1=$ never, with the scale's 18 negative value items graded in the opposite direction, from $5=$ never, down to $1=$ always. In theory, therefore, it is possible to obtain a score ranging anywhere from 40 to 200 points, with 10 to 50 points available from each sub-category. Also, there is no break point. A high score obtained from the scale indicates that the perception of decision making is high, while a low score indicates that perception is low $(14,15)$.

\subsection{Ethical Considerations}

Approval was taken from Istanbul Medipol University's Ethics Committee (10840098-604.01.01-E.11891) before the study. Written permission was taken from the school where the study was conducted. The aims and intended benefits of the study were explained to the participating students by the researchers, who were in fact at the same time the instructors of the course. Verbal consent was obtained from students in accordance with the usual protocol for volunteers.

\subsection{Data Analysis}

The Licensed SPSS 16.0 (Statistical Package for Social science for Windows, Version 16.0) was used for the data analysis. Results were evaluated within the $95 \%$ confidence interval, at the significance level of $p<0.05$. The nominal variables were rated for frequency and percentage; ordinal variables were rated for the minimum, maximum, median values, mean and standard deviation. Shapiro-Wilk test was used to examine the normal distribution. Because of non-normally distributed the Mann-Whitney $U$ test was used for comparison between descriptive analyses (frequency, percentage, mean $\pm S D$, median) and variables. Spearman's correlation technique was used to determine the relationship between Nursing Students' Clinical Decision Making in Nursing Scale and Subscales and Perception of Nursing Diagnoses Scale mean scores.

\section{RESULTS}

All the participants followed the 'Fundamentals of Nursing I and II' theoretical course and laboratory education programme, and over the same period provided for the care needs of at least 7 patients in line with the nursing process.
$77.1 \%$ of the participants were women, with an average age of 19.09 , and their average grade from the Fundamentals of Nursing course was $74.23 \pm 9.41$.

The total of the PND score for the ADLs group was 2.45 \pm 0.55 , while for the FHP group it was $2.31 \pm 0.27$. The difference in the incidence of value was not significant ( $p=$ 0.271). According to FHP and ADLs groups, there was not a statistically significant difference in the PND subscales $(p>$ 0.05) (Table 1).

Table 1. Nursing Students' Perception of Nursing Diagnoses Scale and Subscales: $A D L s$ and FHP

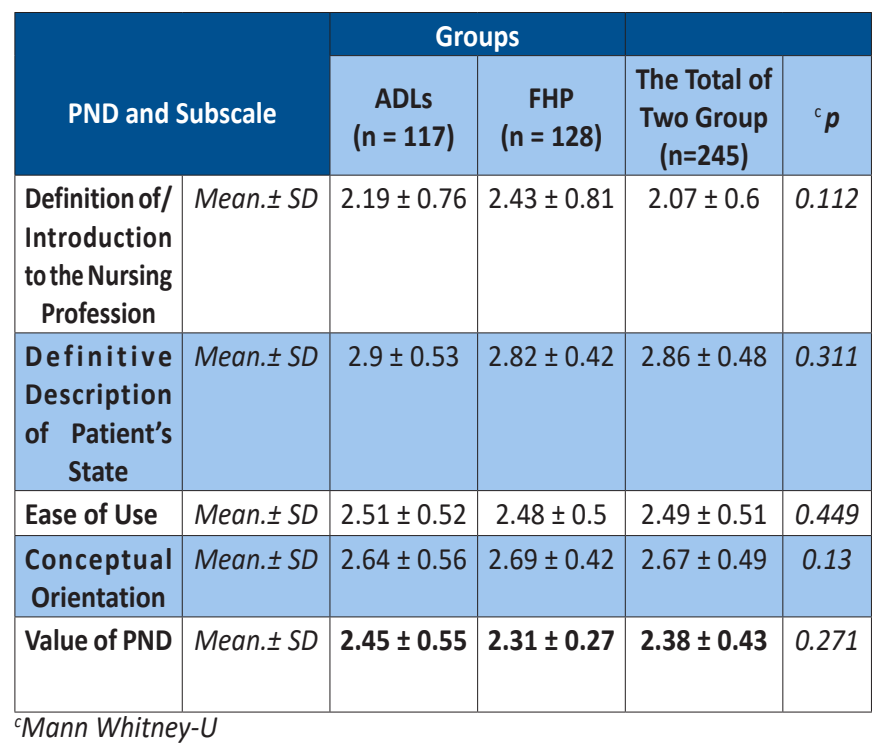

ADLs: A model of nursing care based on activities of daily living; FHP: Functional Health Patterns; PND: Perception of Nursing Diagnoses Survey

The total of the CDMNS score mean of the ADLs group was $147.44 \pm 12.95$, and the mean of the FHP group was $154.3 \pm 12.29$. A statistically significant difference was detected between the groups $(p=0.00)$. Also the mean of the subscales score FHP group was found to be higher than that for the ADLs group and the differences statistically significant: 'canvassing of objectives and values' $(p=0.006)$, 'evaluation and re-evaluation of consequences' ( $p=0.001$ ), and 'search for information and unbiased assimilation of new information' $(p=0.00$ ) (Table 2).

There were found to be significant differences between the total of CDMNS and subscale, and the total of PND $(p<0.01)$ (Table 3).

Also, according to the results comparing the relationship between the exam notes of the Fundamentals of Nursing course and the total scores of CDMNS-Tr, there was a statistically significant correlation $(p<0.01)$. But the relationship between the exam notes of the Fundamentals of Nursing course and the total scores of PND did not show a statistically significant correlation $(p<0.05)$. 
Table 2. Clinical Decision Making in Nursing Scale and Subscales: ADLs and FHP

\begin{tabular}{|c|c|c|c|c|c|}
\hline \multirow{2}{*}{\multicolumn{2}{|c|}{ CDMNS and Subscale }} & \multicolumn{2}{|c|}{ Groups } & \multirow[b]{2}{*}{$\begin{array}{c}\text { Total } \\
(n=245)\end{array}$} & \multirow[b]{2}{*}{${ }^{\mathrm{c}} \boldsymbol{p}$} \\
\hline & & \multirow{2}{*}{$\begin{array}{c}\text { ADLs } \\
(n=117) \\
26-50 \\
(39)\end{array}$} & \multirow{2}{*}{$\begin{array}{c}\text { FHP } \\
(n=128)\end{array}$} & & \\
\hline \multirow{2}{*}{$\begin{array}{l}\text { Search for } \\
\text { alternatives } \\
\text { or options }\end{array}$} & $\begin{array}{l}\text { Min-Max } \\
\text { (Median) }\end{array}$ & & & $\begin{array}{c}26-50 \\
(39)\end{array}$ & \multirow[t]{2}{*}{0.037} \\
\hline & Mean. $\pm S D$ & $\begin{array}{c}38.66 \pm \\
4.47\end{array}$ & $39.66 \pm 3.83$ & $\begin{array}{c}39.18 \pm \\
4.17\end{array}$ & \\
\hline \multirow{2}{*}{$\begin{array}{l}\text { Canvassing of } \\
\text { objectives and } \\
\text { values }\end{array}$} & $\begin{array}{l}\text { Min-Max } \\
\text { (Median) }\end{array}$ & $\begin{array}{c}28-44 \\
(35)\end{array}$ & $26-47(36)$ & $\begin{array}{c}26-47 \\
(35)\end{array}$ & \multirow[t]{2}{*}{$0.006^{*}$} \\
\hline & Mean. $\pm S D$ & $\begin{array}{l}35 \pm \\
3.43\end{array}$ & $36.35 \pm 3.87$ & $\begin{array}{c}35.71 \pm \\
3.72\end{array}$ & \\
\hline \multirow{2}{*}{$\begin{array}{l}\text { Evaluation and } \\
\text { re-evaluation of } \\
\text { consequences }\end{array}$} & $\begin{array}{l}\text { Min-Max } \\
\text { (Median) }\end{array}$ & $\begin{array}{c}30-50 \\
(39)\end{array}$ & $30-48(41)$ & $\begin{array}{c}30-50 \\
(40)\end{array}$ & \multirow[t]{2}{*}{$0.001 *$} \\
\hline & Mean. $\pm S D$ & $\begin{array}{c}38.58 \pm \\
4.26\end{array}$ & $40.37 \pm 4.02$ & $\begin{array}{c}39.5 \pm \\
4.22\end{array}$ & \\
\hline \multirow{2}{*}{$\begin{array}{l}\text { Search for } \\
\text { information } \\
\text { and unbiased } \\
\text { assimilation } \\
\text { of new } \\
\text { information }\end{array}$} & $\begin{array}{l}\text { Min-Max } \\
\text { (Median) }\end{array}$ & $\begin{array}{c}26-45 \\
(35)\end{array}$ & $31-84$ (37) & $\begin{array}{c}26-84 \\
(37)\end{array}$ & \multirow[t]{2}{*}{$0.00 *$} \\
\hline & Mean. $\pm S D$ & $\begin{array}{c}35.17 \pm \\
3.56\end{array}$ & $37.9 \pm 5.39$ & $36.6 \pm 4.8$ & \\
\hline \multirow[t]{2}{*}{$\begin{array}{l}\text { Total of } \\
\text { CDMNS-Tr }\end{array}$} & $\begin{array}{l}\text { Min-Max } \\
\text { (Median) }\end{array}$ & $\begin{array}{c}112-180 \\
(146)\end{array}$ & $\begin{array}{c}124-186 \\
(154)\end{array}$ & $\begin{array}{c}112-186 \\
(151)\end{array}$ & \multirow[t]{2}{*}{$0.00 *$} \\
\hline & Mean. $\pm S D$ & $\begin{array}{c}147.44 \pm \\
12.95\end{array}$ & $\begin{array}{c}154.3 \pm \\
12.29\end{array}$ & $\begin{array}{c}151.02 \pm \\
13.04\end{array}$ & \\
\hline
\end{tabular}

'Mann Whitney-U; *p<0.01

ADLs: A model of nursing care based on activities of daily living; FHP: Functional Health Patterns; CDMNS: Clinical Decision Making in Nursing Scale

Table 3. The Relationship between Nursing Students' Clinical Decision Making in Nursing Scale and Subscales and Perception of Nursing Diagnoses Scale

\begin{tabular}{|c|c|c|}
\hline \multirow[t]{2}{*}{ CDMNS and Subscale } & $\begin{array}{l}\text { Total } 0 \\
\qquad n=2\end{array}$ & $\begin{array}{l}\text { f PND } \\
45)\end{array}$ \\
\hline & $\mathbf{r}$ & $p$ \\
\hline Search for alternatives or options & -0.254 & $0.00^{*}$ \\
\hline Canvassing of objectives and values & -0.194 & $0.002^{*}$ \\
\hline Evaluation and re-evaluation of consequences & -0.232 & $0.00^{*}$ \\
\hline $\begin{array}{l}\text { Search for information and unbiased assimilation } \\
\text { of new information }\end{array}$ & -0.242 & $0.00^{*}$ \\
\hline The Total of CDMNS-Tr & -0.281 & $0.00 *$ \\
\hline
\end{tabular}

CDMNS: Clinical Decision Making in Nursing Scale; PND: Perception of Nursing Diagnoses Survey

\section{DISCUSSION}

Perceptions regarding nursing diagnosis of students and the difference of two models

The nursing diagnosis is the second step of the nursing process. Scientifically-based nursing diagnosis can be described as a clinical judgement about individual, family and community experiences or responses to actual or potential health problems or life processes $(10,11)$. Nursing diagnoses determine the way that nursing knowledge is applied. At the same time they are important for their contribution to the autonomy of nursing as a distinct discipline and in providing a standard nomenclature (16).

The correct use of nursing diagnoses serves to increase patient safety and improve health care quality $(17,18)$. Internalisation of the importance of correct nursing diagnoses is achieved through nursing education. A study conducted by El-Rahman et al. indicated that Jordanian nursing students perceived nursing diagnoses positively (19). In a study in Turkey by Hakverdioğlu et al., most of the students stated that nursing diagnoses were a priority in care practices (20). In the study which initially developed the PND scale, the value of the PND score was found to be 2.94. In the study into the validity and reliability of its Turkish version, the value was determined to be 2.48 (12). Another study, conducted by Halverson et al. on nurses from Minnesota, found the value of the PND score to be 3.09 (21). In the current study, the value of the PND score for nursing students from the two different schools was found to be $2.38 \pm 0.43$. These findings show similarities to the results of other studies. From the results, it can be concluded that the use of nursing diagnoses is positively perceived. It is considered that in both schools featured in this study, the results are compatible with the education offered. This accords with the statement commonly found in nursing program learning outcomes: ' $\mathrm{He} /$ she has acquired sufficient knowledge to enable them to meet the health needs of individuals, family and community by means of an individual and holistic approach, applied through the use of nursing process'. At the same time, the subscales of PND was perceived samely by students receiving an FHP and ADLsbased education.

Clinical decision-making perception of students and the difference of two models.

Decision making in clinical settings is a necessary factor in the provision of safe, quality care for the community and in improving patient care outcomes. Decision making in clinical settings is the way nurses express their knowledge in practice (22-24). It is important to determine the perception of nursing students in clinical decision making, and to evaluate their decision-making perception. In the current study, students' total CDMNS score of $151.02 \pm 13.04$ shows that their decision-making perception in clinical settings are in process of development. One study found that the undergraduate nursing students total of CDMNS score was $160.82 \pm 10.75$ (14). The study conducted by Dicle and Durmaz, students' total of CDMNS score was specified as $156.90 \pm 11.11$ and indicates that their decision-making perception in clinical settings are in process of development (13). Clinical decision making in a nursing context can be regarded as the process of putting acquired nursing knowledge into practice (23). In this study, the detection of a significant relationship between the 
Fundamentals of Nursing exam score and the total of CDMNS score confirms this information.

It was determined that, with regard to the total CDMNS score, students receiving FHP based education did better than those receiving ADLs based education. This difference was found to be statistically significant. These results can be explained by the fact that NANDA-I diagnoses are classified according to FHP and thus it can make the decision easily. Besides, it should be noted that clinical decision making can also be affected by a range of other factors, such as: theoretical knowledge, personal traits, complexity of the decision-making situation (22).

Relationship between students' perceptions regarding nursing diagnoses and clinical decision making

The current study results show that there is a positive relationship between the subscales of CDMNS and the value of PND. Nursing diagnosis is a clinical judgment about the real or potential health problems / life processes of the individual, the family and the society (25). Positive perception of nursing diagnoses influences the clinical decision-making process of the individual's health care needs. Clinical decision-making perception being improved facilitates making a correct nursing diagnosis in the health care process. For this reason, there being a positive relationship between students' perceptions regarding nursing diagnoses and clinical decision making in our study is an expected outcome.

\section{Limitations}

The research was limited to the nursing departments in which the study was conducted and the results cannot be generalised. Ideally, the study should be repeated for further sample groups.

\section{CONCLUSION}

The two models most often used in nursing education in Turkey are ADLs and FHP. However, there is no information available as to why one is chosen over another in nursing programs across the country. At the same time, it is not clear how students perceive differences between the two models in terms of effectiveness or ease of use. This study attempts to explain the relationship between, on the one hand, the perception of nursing diagnoses and clinical decision making, and, on the other, the two models which constitute the basis of the education provided by nursing schools. No difference was found in perception of nursing diagnoses between the groups who were taught patient assessment with the two different models. It was observed that students receiving the FHP-based education were better than their counterparts who received the ADLs-based education with regard to clinical decision-making perception. However, it should be remembered that clinical decision making may be affected by a number of different factors. For example, in the study it was observed that students who attained good exam scores from the Fundamentals of Nursing course showed high clinical decision-making ability. In this light it is recommended that, ideally, a further evaluation should be carried out which takes more of these factors into account. It is likely too that there would be definite benefits from repeating the study with a larger sample and in different schools.

\section{Implication for Nursing Knowledge}

This study helps to understand the impact of two nursing models that are widely used in nursing schools in Turkey, on the perception of nursing diagnosis and clinical decision making. As a result of the study, it is seen that the two nursing models have different advantages in comparison to each other. Academic staff can decide which to choose in accordance with their expectations from the students. Thus, study results will shed light on the reason why they choose one model but not the other one.

\section{REFERENCES}

[1] April M, Bassendowski S. The history of evidenced-based practice in nursing education and practice. J Prof Nurs 2017; 33:51-55.

[2] Boztepe H, Terzioğlu F. Skill assessment in nursing education. Journal of Anatolia Nursing and Health Sciences 2012; 16:5764.

[3] Güner P, Terakye G. The level of determination nursing diagnosis of senior nursing school students. Journal of Cumhuriyet University School of Nursing 2000; 4:9-15. (Turkish)

[4] Akça NK, Taş̧̧ı S. Nursing education and critical thinking. Mersin University Journal of the Faculty of Education 2009; 5:187-195. (Turkish)

[5] Gorton LK, Hayes J. Challenges of assessing critical thinking and clinical judgement in nurse practitioner students. J Nurs Educ 2014; 53:26-29.

[6] Andsoy II, Güngör T, Dikmen Y, Nabel E. B. Difficulties that nurses have in using care plan. J Contemp Med 2013; 3(2):8894. (Turkish)

[7] Vicdan AB, Karabacak B, Alpar SE. Classification of 2012-2014 NANDA-I nursing diagnostic susing the nursing model based on activities of living. International Journal of Human Sience 2015; 12:1625-1626.

[8] Hakverdioglu G, Korhan AE, Erdemir F, Muller-Staub M. Nursing diagnoses determined by first year students: a vignette study. Int J Nurs Knowl 2014; 25:39-42.

[9] Hemşirelik yönetmeliğinde değişiklik yapılmasına dair yönetmelik 2011 (cited 2019 April 1) Available from: https:// www.resmigazete.gov.tr/eskiler/2011/04/20110419-5.htm

[10] Birol L. Hemşirelik Süreci. İzmir: Etki Yayınları; 2009 (Turkish).

[11] Carpenito-Moyet LJ. Nursing Diagnosis: Application to Clinical Practice. 13th ed. Philadelphia: Lippincott, Williams \& Wilkins; 2010.

[12] Akın-Korhan E, Hakverdioğlu-Yönt G, Ak B, Erdemir F. Analysis of Turkish validity and reliability of perception of nursing diagnosis. HEMAR-G. 2013; 15:13-25. (Turkish)

[13] Dicle A, Durmaz EA. Examination of clinical decision-making perceptions of nursing students. New Educ Review 2013; 33:134-144.

[14] Edeer AD, Sarikaya A. Adaptation of clinical decision making in nursing scale to undergraduate students of nursing: The study of reliablity and validity. IJPES 2015; 2:1-9. 
[15] Jenkins $\mathrm{H}$. A research tool for measuring perceptions of clinical decision making. J Prof Nurs 1985; 1:221-229.

[16] Aşti TA, Karadağ A. Fundemental of Nursing. İstanbul: Akademi Basın ve Yayıncılık; 2012 (Turkish).

[17] Turk G, Tugrul E, Sahbaz M. Determination of nursing diagnoses used by students in the first clinical practice. Int J Nurs Knowl 2013; 24:129-133.

[18] Zaybak A, İsmailoğlu GE, Özdemir H. Examining the difficulties experienced by nurses in the nursing process applications. Journal of Anatolia Nursing and Health Sciences. 2016; 19:269277. (Turkish)

[19] El-Rahman MA, Kalaldeh MT, Malak MZ. Perceptions and attitudes toward NANDA-I nursing diagnoses: A cross-sectional study of Jordanian nursing students. Int J Nurs Knowl 2017; 28:13-18.

[20] Hakverdioglu GY, Khorsid L, Eser I. Examination of nursing diagnoses used by nursing students and their opinions about nursing diagnoses. Int J Nurs Terminol Classif 2009; 20:162168.

[21] Halverson ER, Beetcher EL, Scherb AC, Olsen G, Frost M, Orth $\mathrm{K}$. Minnesota nurses' perceptions of nursing diagnoses. Int J Nurs Terminol Classif 2011; 22:123-131.

[22] Sucu G, Dicle A, Saka O. Decision making in clinical nursing: decision-making models and affecting factors. HEMAR-G. 2012; 9:52-60. (Turkish)

[23] Yıldırım A, Taşcı S. Clinical decision-making on the effect of critical thinking in nursing. Balikesir Health Sciences Journal. 2013; 2:186-191. (Turkish)

[24] Janet LM, Kathie L, Sydnee S, Nathan D. New graduate nurse experiences in clinical judgment: What academic and practice educators need to know. Nurs Educ Perspect 2018; 39:201207.

[25] Kaya H. NANDA International. Nursing Diagnoses: Definitions \& Classification. 10th ed. Istanbul: Nobel Tıp Kitabevleri; 2017 (Turkish). 